\title{
Removal of PFAS from Water by Plants
}

\author{
Maria Greger*, Tommy Landberg and Harmanjit Kaur \\ Department of Ecology, Environment and Plant sciences, Stockholm University, Sweden
}

Submission: May 12, 2021; Published: June 04, 2021

*Corresponding author: Maria Greger, Department of Ecology, Environment and Plant sciences, Stockholm University, 10691 Stockholm, Sweden.

Abstract

Perfluorinated alkylated substances (PFAS) has been produced the last five decades as wetting agents, stain-resistant treatments, lubricants, impregnation sprays and corrosion inhibitors. Among the most common and toxic are perfluoro octane sulfonate (PFOS) and perfluorooctanoic acid (PFOA), which are found among others in blood, soil and water. They need to be removed from water and the aim was to investigate the removal capacity by a terrestrial plant, Salix viminalis, two emergent plants, Carex rostrata and Euriophorum angustifolium and one submerged plant, Elodea canadensis. Leakage water from a landfill were treated with plants during up to 14 days. Results showed that the removal capacity was in the order: S. viminalis $<$ E. angustifolium $<$ C. rostrata $=$ E. canadensis. The removal by C. rostrata and E. canadensis increased linearly with time. PFOS and PFOA decreased with 63 and 42\%, respectively, in the water after $12 \mathrm{~d}$ treatment with C. rostrata. Both PFOS and PFOA was taken up in tissue of the C. rostrata and E. canadensis: around $9 \%$ of PFOS/PFOA was found in the plant. PFOA was more able to be translocated to the shoot than PFOS. About 5\% PFOS/PFOA did disappear from the system, indicating that some of PFOS and PFOA possible had been degraded or transformed. However, no degrading enzymes, peroxidase or laccase, enzymes earlier shown to degrade PFAS, were detected in the water. One can conclude that the wetland plants were able to remove various PFAS from water and possible be used in phytoremediation.

Keywords: PFOS; PFOA; Plants; Remediation; Water

\section{Introduction}

Perfluorinated alkylated substances (PFAS) are aliphatic compounds where most carbons in a carbon chain are bound to fluoride instead of hydrogen atoms. PFAS have been manufactured for half a century for use as wetting agents, stain-resistant treatments, lubricants, impregnation sprays and corrosion inhibitors in foam extinguishers, clothing, leather, paper and more $[1,2]$. These substances are very persistent, very mobile in the environment and highly toxic.

Two of the most common and toxic ones are perfluoro octane sulfonate (PFOS) and perfluorooctanoic acid (PFOA) and have been detected among others in water, blood, soil and sediment [3]. The main route of exposure to humans are probably dietary intake [4]. Both PFOS and PFOA are water-soluble ionic surfactants and are found in ground water and other natural waters, where it ends up after e.g., use of fire-fighting foams. They will therefore be present in drinking water. Since water is used for irrigation of food and fodder crops, and plants take up PFAS-compounds [5-7] they will end up in food. The PFAS-compounds are toxic to humans and PFOS and PFOA increase e.g., the activity of free radicals and cellular apoptosis [8].

There is a need for remediation of natural water from PFAS around the world. Phytoremediation of PFAS is a possibility and both PFOA and PFOS can be taken up by plants from soil [9] and from hydroponic cultures [10]. There were measurable contents of PFOS and PFOA in the vegetative parts of the plants also after treatment in very low levels of PFOA and PFOS in the medium. More of these substances was found in roots than in shoots [5]. Pilot studies with wetland plants showed that roots of four different aquatic plants species absorbed PFOS and PFOA from water [11]. Up to 82 and $95 \%$ of PFOA and PFOS, respectively, were removed from the water 15 days after treatment. Authors claimed that phytoremediation and soil sorption were the best methods to remediate PFAS. Recently, Wang et al. [12] claimed that submerged plants had higher bioaccumulation factor of PFOS and PFOA than emergent plants collected from a wetland with PFAS polluted water.

Treatment of PFAS contaminated water using plants will decrease PFAS in the water and there are various possible ways it can be performed. Plants may excrete enzymes or promote microbial production of enzymes that degrade PFAS in the water. They can remove PFAS or the degraded PFAS compounds from the water by uptake. In the tissue, PFAS or the degraded compounds will either be accumulated or degraded by the use of cellular or extra cellular enzymes. Both laccase and peroxidase were shown to degrade PFOA $[13,14]$, and those enzymes were produced in 
the plants and were used in cell wall polymerization and lignin synthesis [15]. These enzymes can be found in the rhizosphere [16].

The present work aiming at investigate the removal capacity by various plant types (terrestrial, emergent and submerse plants) of PFAS from contaminated leakage water originating from a landfill.

\section{Materials and Methods}

\section{Materials}

Plants chosen in this experiment were those which can cope up with oxygen deficient environments, i.e., water solution. One terrestrial plant species, willow, Salix viminalis, two emergent plant species common cotton grass, Europhorum angustifolium, and bottle sedge Carex rostrata and one submergent plant species Canadian pondweed, Elodea canadensis were used. Prior to the experiment, one-year old cuttings from $S$. viminalis were cultivated for 3 weeks in $100 \mu \mathrm{M}$ Ca $\left(\mathrm{NO}_{3}\right)_{2}$ according to Landberg \& Greger [17] in order to grow shoots and roots. Seeds from $E$. angustifolium were cultivated according to Javed et al. [18]. Shoots of E. canadensis $15 \mathrm{~cm}$ in length were collected from the department green house. Carex rostrata was originally collected from the Stockholm area [19] and cultivated in 25\% Hoagland medium prior to the experiment.

Leakage water collected from a landfill at Dragmossen, Älvkarleby, in Sweden (60³3’50.5”N 17³0'1.9”E), was used. The content of various PFAS of the untreated water is shown in Table 1.

Table 1: Concentration of various PFAS substances in the water at the beginning and after14 days of treatment with $E$. angustifolium. $\mathrm{n}=2-3, \pm \mathrm{SE}$. Detection limit $10 \mathrm{ng} \mathrm{L}^{-1} .{ }^{*}$, significant difference from start value.

\begin{tabular}{|c|c|c|c|}
\hline PFAS-substans & $\begin{array}{c}\text { At Start } \\
\text { ng L }\end{array}$ & $\begin{array}{c}\text { After 14 d } \\
\text { ng L }\end{array}$ & $\begin{array}{c}\text { Removal } \\
\text { \% }\end{array}$ \\
\hline PFOS & 135 & $105 \pm 1$ & $22.3 \pm 0.63^{*}$ \\
\hline PFHpA & 212 & $182 \pm 3$ & $14.0 \pm 1.41^{*}$ \\
\hline PFOA & 810 & $709 \pm 7$ & $12.5 \pm 0.80^{*}$ \\
\hline PFBS & 84 & $74 \pm 1$ & $12.5 \pm 0.60^{*}$ \\
\hline PFHXA & 366 & $326 \pm 2$ & $10.8 \pm 0.54^{*}$ \\
\hline PFPeA & 258 & $236 \pm 1$ & $8.5 \pm 0.19^{*}$ \\
\hline PFBA & 846 & $804 \pm 5$ & $5.0 \pm 0.53^{*}$ \\
\hline PFHxS & 51 & $52 \pm 1$ & $0 \pm 2.45$ \\
\hline
\end{tabular}

PFOA: perfluorooctanoicacid; PFOS: perfluorooctanesulfonicacid; PFHpA: perfluoroheptanoicacid; PFBS: Perfluorobutanesulfonate; PFHxA: Perfluorohexanoicacid; PFPeA: perfluoropentanoicacid; PFBA: perfluorobutanoicacid; PFHxS: Perfluorohexanesulfonicacid.

The following PFAS were also analysed in experiment 2 but had values under the detection limit: PFNA: Perfluorononanic acid; PFDA: Perfluorodecanic acid; PFUnDA: Perfluoroundecanic acid; PFDoDA: Perfluorododecanic acid; PFHpS: Perfluoroheptane Sulfonic Acid; PFDS: Perfluorodecane Sulfonic Acid; PFOSA: Perfluoroctane Sulfonamide; 6:2FTS: 6:2 Fluorotelomeric Sulfonate; 8:2FTS: 8:2 Fluorotelomeric Sulfonate.

\section{Experiments}

In all cases, $1 \mathrm{~L}$ leakage water in $1 \mathrm{~L}$ black pots was used. The terrestrial and emergent plants were mounted in black styrophoam plates, which then were floated on the leakage water in the black pots. In the case of submergent plants, the whole plants were placed in the leakage water of the pot with no black styrophoam plate. In each pot, three plants were planted per pot, except for $C$. rostrata where one plant was used. Value of the biomass used per liter of leakage water is found in Table 2. The leakage water was aerated for continuous movement of the solution in order to avoid depletion zones. The experiments were carried out in a climate chamber with a day $/$ night regime of $16 / 8 \mathrm{hrs}$ at $23 / 19^{\circ} \mathrm{C}$. During daytime the PPFD was $230 \mu \mathrm{mol} \mathrm{s}^{-1} \mathrm{~m}^{-2}$.

In the first experiment, $S$. viminalis and E. angustifolium were cultivated for 14 days in the leakage water, which was sampled at the beginning and after 14 days cultivation. The experiment was performed with three replicates and PFOS and PFOA were analyzed.

In the second experiment, E. angustifolium was cultivated for 14 days, and leakage water samples were collected in the beginning and after 14 days. The experiment was performed in duplicate and 17 different PFAS substances were analyzed.

In the third experiment, $C$. rostrata was grown for 12 days in the leakage water, which was sampled in the beginning and then after 12 days. Two replicates were used and PFOS and PFOA were analysed.

In the fourth experiment, $C$. rostrata and E. canadensis were used, cultivated for 3 days and water samples were taken at the beginning and after 1 and 3 days. The experiment was performed in triplicate, and after day 3 in the water plants were sampled. Water, roots and shoots were analyzed on PFOS and PFOA.

Analysis of PFAS was performed by the accredited laboratory ALS Scandinavia in Luleå, Sweden. 


\section{Analysis of degrading enzymes in the leakage water}

Elodea canadensis and C. rostrata were cultivated in leakage water as described above, in triplicates, as well as in tap water in triplicate up to five days. At day 1, 3 and 5, respectively, $10 \mathrm{ml}$ samples were collected in order to analyze PFAS degrading enzymes released from the plants into the water. All the samples were analyzed using vertical gel electrophoresis system using $10 \mathrm{x}$ $10.5 \mathrm{~cm}$ glass slabs. Agarose, $0.8 \%$, gel plates were fixed and $7.5 \mu \mathrm{l}$ SYBR safe stain was added to $75 \mathrm{ml}$ TBE electrophoresis buffer (20mM Tris base, $20 \mathrm{mM}$ Boric acid and 0.4mM EDTA). Samples were run at a voltage of $90-95 \mathrm{~V}$ using Hoefers current supply. Samples were concentrated using freeze dryer for nearly 7-8hrs and were tested using gel electrophoresis plates both before and after drying treatment.

\section{Calculations}

Distribution of PFAS in the plant between roots and shoots were calculated as

Distribution $=\frac{\text { PFAS concentration in the shoot }}{\text { PFAS concentration in the root }}$

Translocation to the shoot of PFAS, which has been taken up was calculated as

Translocation $(\%)=\frac{\text { Content of PFAS in shoot }}{\text { Content of PFAS in whole plant }} \times 100$

Uptake efficiency of PFAS, i.e., how much of PFAS in the water at start is found in the plant was calculated as

Uptake efficiency $(\%)=\frac{\text { Content of PFAS in total plant material }}{\text { Total content of PFAS in the water at start }} \times 100$
Statistical treatment was performed using the "R"-package (version 4.0; linkhttps://www.r-project.org). Data has been tested for normality using Shapiro-Wilk test (not shown). All data is categorical and therefore ANOVA has been used. Significance was set to $P=0.05$. Significances in tables are indicted with significant star or/and letters. The majority of data were replicated; however, few data have no replicates and has been tested using one-sample z-test against a mean.

\section{Results}

The initial concentration of PFOS and PFOA in the leakage water was $135 \pm 30(\mathrm{SE})$ and $820 \pm 30 \mathrm{ng} \mathrm{L}^{-1}$, respectively, in all the four experiments. The concentration in the water did not change during the experimental time in the controls, i.e., when plants were absent (not shown).

Of all PFAS-compounds detected in the water, except perfluoro hexane sulfonic acid (PFHxS), a significant part was removed from the water by E. angustifolium (Table 1). The removal was significant for PFOA, PFOS, PFHpA, (perfluoro heptanoic acid), PFBS (perfluoro butane sulfonate), PFHxA (perfluoro hexanoic acid), PFPeA (perfluoro pentanoic acid) and PFBA (perfluoro butanoic acid). Highest removal rate for PFOS was recorded to be $22 \%$

The longer the treatment time the more was removed (Table 2 \& Figure 1). In all the four experiments, PFOS was removed from the water to a higher extent than PFOA (Table 2).

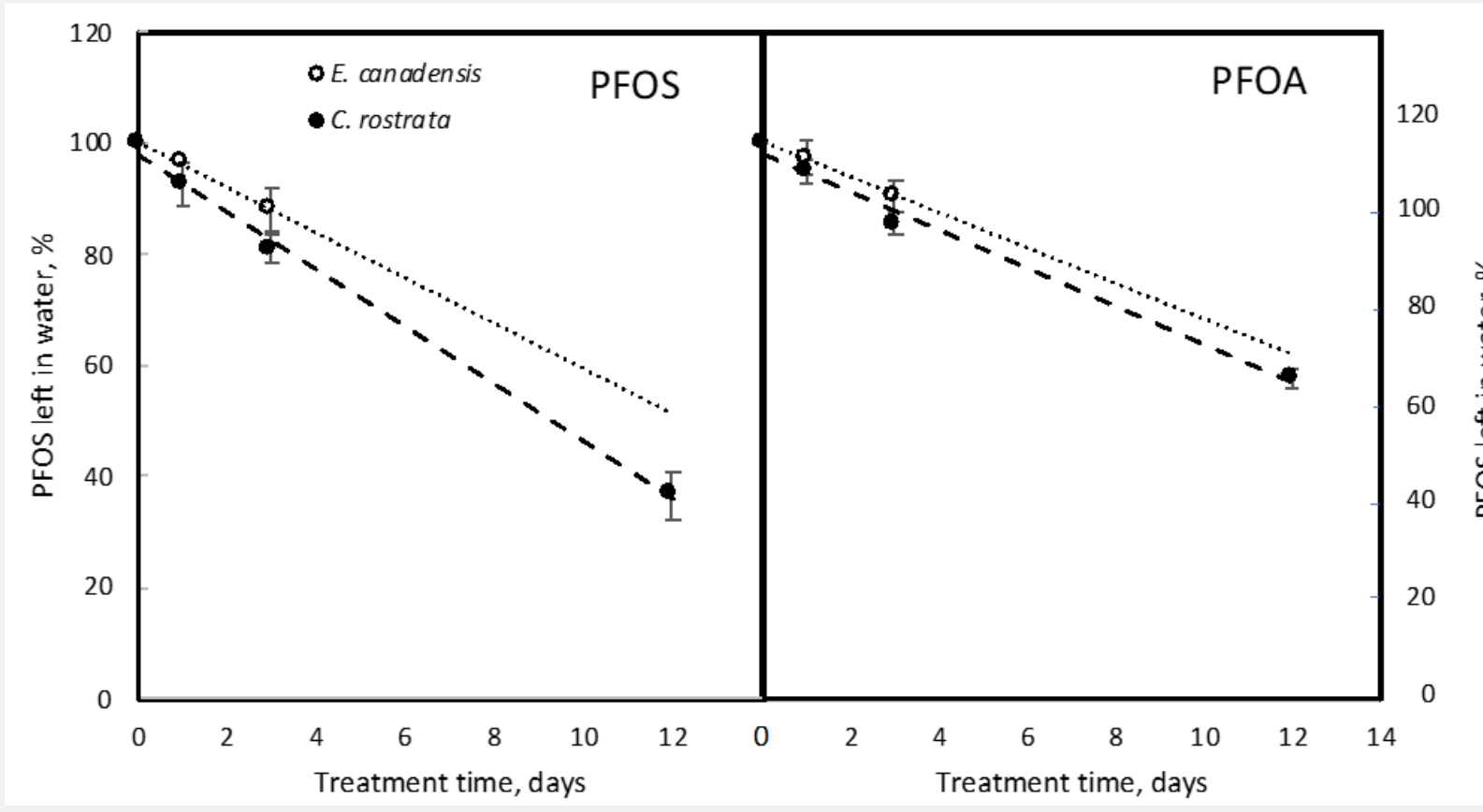

Figure 1: Decrease of PFOA and PFOS in leakage water after treatment for up to 12 days with Elodea canadensis and Carex rostrata. Line

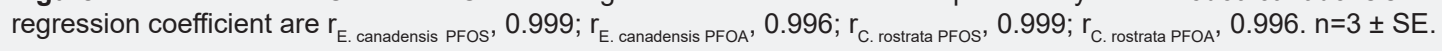




\section{International Journal of Environmental Sciences \& Natural Resources}

Table 2: Removal of PFOS and PFOA with plants calculated as \% removed from $1 \mathrm{~L}$ solution after 3,12 or 14 day-treatment. Biomass of the plantpart in the one $L$ water is indicated. $n=2-3, \pm S E$. *Significant different from start.

\begin{tabular}{|c|c|c|c|c|c|c|c|c|c|c|c|c|}
\hline \multirow{3}{*}{ PFAS } & \multicolumn{4}{|c|}{ Experiment 1} & \multirow{2}{*}{\multicolumn{2}{|c|}{$\begin{array}{c}\text { Experiment } 2 \\
\text { E. angustifolium }\end{array}$}} & \multirow{2}{*}{\multicolumn{2}{|c|}{$\begin{array}{c}\text { Experiment } 3 \\
\text { C. rostrata }\end{array}$}} & \multicolumn{4}{|c|}{ Experiment 4} \\
\hline & \multicolumn{2}{|c|}{ S. viminalis } & \multicolumn{2}{|c|}{ E. angustifolium } & & & & & C. ros & rata & E. can & densis \\
\hline & $\% 14 d^{-1}$ & gFWroot & $\% 14 d^{-1}$ & gFWroot & $\% 14 d^{-1}$ & gFWroot & $\% 12 d^{-1}$ & gFWroot & $\% 3 d^{-1}$ & gFWroot & $\% 3 d^{-1}$ & gFWplant \\
\hline PFOA & $7.7 \pm 4.9$ & $28.3 \pm 2.6$ & $12.6 \pm 2.1^{*}$ & $15.3 \pm 1.6$ & $12.5 \pm 0.8^{*}$ & $17.4 \pm 2.47$ & $42.1 \pm 1.6^{*}$ & $44.5 \pm 2.7$ & $9.4 \pm 3.4^{*}$ & $57.3 \pm 2.5$ & $14.3 \pm 2.5^{*}$ & $91.5 \pm 4.9$ \\
\hline PFOS & $8.6 \pm 2.4$ & & $16.5 \pm 2.5^{*}$ & & $22.3 \pm 0.6^{*}$ & & $63.3 \pm 4.2^{*}$ & & $13.1 \pm 5.4^{*}$ & & $19.0 \pm 3.0^{*}$ & \\
\hline
\end{tabular}

The first experiment with terrestrial and emergent plants, $S$. viminalis and E. angustifolium, showed that within 14 days $S$. viminalis did not significantly remove any PFOS or PFOA from the water (Table 2). However, E. angustifolium did remove about 13 and $17 \%$ of PFOA and PFOS, respectively, even with less root biomass than $S$. viminalis.

In the second experiment, E. angustifolium removed 13\% PFOA and 22\% PFOS after 14 days similarly as in the first experiment (Table 2). The other detected PFAS analyzed, (PFAB, PFPeA, PFHxA, PFHpA, PFBS) was also removed from the water, between $5-14 \%$ by E. angustifolium (Table 1).

In the third experiment, $C$. rostrata showed higher removal than E. angustifolium; $42 \%$ PFOA and $64 \%$ PFOS was removed by $C$. rostrata after 12 days of the treatment (Table 2). Compared with $E$. angustifolium in the second experiment, 4 times more PFOS and 3 times more PFOA was removed despite 2.6 times more roots and 2 days shorter removal period.

In the fourth experiment $C$. rostrata and E. canadensis was tested for removal efficiency. After 3 days treatment $C$. rostrata removed $9 \%$ PFOA and 13\% PFOS while E. canadensis removed $14 \%$ PFOA and $19 \%$ PFOS (Table 2). Both plants removed similarly (Figure 1, Table 2), and the removal was related to their submerged biomass (Table 2). Significant removal rate for PFOS and PFOA was observed in both the plants after one day; which gradually increased with time (Figure 1). For C. rostrata, removal rate was faster for PFOS as compared to PFOA and it remained linear for nearly 12 days. The same was shown for E. Canadensis during the 3 days experiment.

Both C. rostrata and E. canadensis accumulated PFOA and PFOS in the tissue (Tab. 3). The accumulation was 8.8 and $12.3 \%$ in C. rostrata and 6.2 and $8.5 \%$ in E. canadensis of the added PFOA and PFOS, respectively. The tissue concentration of PFOA was 6.5 times higher than that of PFOS, similarly as of the water initially. The PFOS concentration was higher in roots than in shoots, while the opposite trend was found for PFOA (Table 4). The shoot: root concentration ratio was significantly higher for PFOA than PFOS. This was also mirrored in that the translocation to the shoot was slightly higher for PFOA than PFOS, although not significant. At day 3 , the uptake efficiency for PFAS substances was about $10 \%$ for both the plants (Table 3). Calculation on PFOA and PFOS in the system showed that 4 and $7 \%$ PFOS and 3 and $8 \%$ PFOA had disappeared from the system after the three days with $E$. canadensis and C. rostrata, respectively.

Table 3: Concentration of PFOA and PFOS in whole plant of Elodea canadensis and Carex rostrata and in the water after three days treatment of leakage water containing 130 and $820 \mathrm{ng} \mathrm{L}^{-1} \mathrm{PFOS}$ and PFOA at start, respectively. Indicated are the uptake efficiency, i.e., how much in \% is found in the plant of that in the water at start as well as in analyse of PFOS and PFOA in the plant water system. $n=3, \pm$ SE. Asterix $\left(^{*}\right)$ indicates value that differ from start

\begin{tabular}{|c|c|c|c|c|c|c|c|c|c|c|c|c|c|c|}
\hline & \multicolumn{7}{|c|}{ Carex rostrata } & \multicolumn{7}{|c|}{ Elodea canadensis } \\
\hline & \multicolumn{3}{|c|}{ Whole plant } & \multirow{2}{*}{$\begin{array}{c}\text { Water } \\
\text { ng }\end{array}$} & \multirow{2}{*}{$\begin{array}{c}\begin{array}{c}\text { Water + } \\
\text { plant }\end{array} \\
\text { ng }\end{array}$} & \multirow{2}{*}{$\begin{array}{c}\begin{array}{c}\text { Differ } \\
\text { from } \\
\text { start }\end{array} \\
\%\end{array}$} & \multirow{2}{*}{$\begin{array}{c}\begin{array}{c}\text { Uptake } \\
\text { efficiency }\end{array} \\
\%\end{array}$} & \multicolumn{3}{|c|}{ Whole plant } & \multirow{2}{*}{$\begin{array}{c}\text { Water } \\
\text { ng }\end{array}$} & \multirow{2}{*}{$\begin{array}{c}\text { Water } \\
+ \text { plant } \\
\text { ng }\end{array}$} & \multirow{2}{*}{$\begin{array}{c}\begin{array}{c}\text { Differ } \\
\text { from } \\
\text { start }\end{array} \\
\%\end{array}$} & \multirow{2}{*}{$\begin{array}{c}\begin{array}{c}\text { Uptake } \\
\text { efficiency }\end{array} \\
\%\end{array}$} \\
\hline & $\begin{array}{c}\text { ng } \\
\text { kgFW }^{-1}\end{array}$ & ng & $\begin{array}{c}\% \text { of } \\
\text { added }\end{array}$ & & & & & $\begin{array}{c}\text { ng } \\
\text { kgFW }^{-1}\end{array}$ & ng & $\begin{array}{c}\% \text { of } \\
\text { added }\end{array}$ & & & & \\
\hline PFOA & $1420 \pm 75$ & $72 \pm 1.7^{*}$ & 8.8 & $703 \pm 16.7 *$ & $775 \pm 16.9 *$ & $5.9 \pm 2.1^{*}$ & $8.4 \pm 2.3^{*}$ & $1560 \pm 85$ & $51 \pm 1.5^{*}$ & 6.2 & $743 \pm 23^{*}$ & $794 \pm 23$ & $3.4 \pm 1.8$ & $6.0 \pm 1.9^{*}$ \\
\hline PFOS & $210 \pm 25$ & $16 \pm 0.5^{*}$ & 12.3 & $105 \pm 3.3^{*}$ & $121 \pm 3.3^{*}$ & $7.0 \pm 2.5^{*}$ & $12.3 \pm 3.1^{*}$ & $230 \pm 20$ & $11 \pm 0.5^{*}$ & 8.5 & $114 \pm 5^{*}$ & $125 \pm 5$ & $3.9 \pm 1.9$ & $8.4 \pm 2.1^{*}$ \\
\hline
\end{tabular}

Table 4: Concentration of PFOS and PFOA in Carex rostrata after 3 days treatment with leakage water contaminated with PFAS. The substances were not detected in control plants. Translocation of PFOS and PFOA to shoot of what has been taken up is indicated. $n=3, \pm S E$. Different letters show significant difference comparing root concentration with shoot concentration as well as PFOS with PFOA translocation and shoot:root concentration ratio, respectively.

\begin{tabular}{|c|c|c|c|c|}
\hline & Root & Shoot & Shoot:Root & \\
\cline { 2 - 5 } & \multicolumn{2}{|c|}{ ng kg-1 } & & $1.42 \pm 0.12 \mathrm{~s}$ \\
\hline PFOA & $1190 \pm 80 \mathrm{a}$ & $1685 \pm 80 \mathrm{~b}$ & $0.76 \pm 0.07 \mathrm{t}$ & $63.8 \pm 5.3 \mathrm{~g}$ \\
\hline PFOS & $250 \pm 20 \mathrm{x}$ & $190 \pm 20 \mathrm{x}$ & $58.7 \pm 7.8 \mathrm{~g}$ & \\
\hline
\end{tabular}


No peptides, nor enzymes could be detected in the cultivation media five days after treatment with E. canadensis or C. rostrata. Thus, no PFAS degrading enzymes were detected in the electrophoresis gel plates from the water samples even after five days of the treatment.

\section{Discussion}

This work showed that the investigated wetland plants were able to remove various PFAS-compounds from water, while the terrestrial plant was not very efficient (Table 2). That wetland plants are more efficient to remove pollutants than terrestrial plants have earlier been discussed by Fritioff \& Greger [20] for heavy metals and Bergquist \& Greger [21] for arsenic. Carex rostrata removed 63\% PFOS and 42\% PFOA after 12 days (Table 2), which can be compared with data by Chen et al. (2012) [11] showing removal of up to $82 \%$ for PFOA and $95 \%$ for PFOS by wetland plants, especially Hygrophila pogonocalyx (Hayata), 15 days after treatment. The higher removal value in the work by Chen et al. [11] might be due to the fact that sediment was included since, in addition to phytoextraction removal works by sorption onto sediment.

While comparing the emergent plants in this study, it was observed that $C$. rostrata was better at removing PFOS and PFOA than E. angustifolium (Table 2). Carex rostrata and the submerged plant, E. canadensis, had a similar removal capacity when biomass was taken into account (Table 2). This means that both roots and shoots work similarly well to remove PFOS and PFOA. What can cause hindrance to the uptake by the shoots is the cuticle, which prevents unnecessary transpiration but also influx into the tissue. However, submergent plants do not have any cuticle and therefore can more easily take up substances and elements from the surrounding medium than aboveground shoots [22].

The concentration of PFOS and PFOA in the plant tissue of $C$. rostrata and E. canadensis was higher than that in the water (Table 3 ), which means these plants are accumulating PFOS and PFOA. The removal of PFOS and PFOA increased with time, where the removal by C. rostrata increased with time at least up to 12 days (Figure 1). Also, Chen et al. [11] found higher removal of PFOS and PFOA with time from aquatic plants. It is less likely that the increase in removal is due to higher uptake with time; since the plants showed saturation in the uptake rates after 8 days when the plant concentration was stabilized [11].

Although, there was not much difference in the uptake efficiency between PFOS and PFOA, the latter was easily translocated to the shoot than PFOS (Table 3). This was shown by the higher PFOA concentration in the shoots as compared with roots; while the opposite was found for PFOS (Table 4). Similar distribution pattern was found in agricultural plants like cabbage, lettuce and tomato $[10,23]$. The difference might be due to the molecular size because PFOA is a smaller molecule than PFOS [24]. The effect of molecular size on uptake and distribution was earlier discussed by Krippner et al. [25] and Garcia-Valcarcel et al. [26]. It is possible that PFOA may be easier to translocate than sulphonates (PFOS) or sulphonates are firmly bound to the root tissue than acids. Another possibility is that these persistent substances partly can be transformed from sulphonates to acids. It is shown that laccases can desulphonate substances [27]. If they then can be transformed to acids is not known by the authors.

In all cases, PFOS was removed to a slightly higher extent than PFOA (Table 2, Figure 1). Plants did also accumulate PFOS more than PFOA (Table 3). The reason might be that the PFOA concentration was much higher than that of PFOS in the medium and it is well known that uptake efficiency of elements decreases with increasing concentration in the medium $[22,28]$. It might also be possible that perfluorooctane sulfonate (PFOS) is easier to take up than perfluorooctanoic acid (PFOS) due to their different chemistry. This corroborates with the work by Wang et al. [12], which show that there was a higher bioaccumulation factor of PFOS than of PFOA in both emergent and submerged plants. The opposite, however, was found by Stahl et al. [9].

When the amount of PFOS and PFOA in the plants (Table 3) is summed up with the amount left in the water after treatment (Table 3) 4-7\% PFOS and 3-6 \% PFOA was missing when compared with the start value (Table 4). The missing amount is significant. The interpretation is that PFAS and PFOA is degraded or transformed by the presence of the plants. It is known that laccases, which are enzymes involved in the lignin process, are capable to degrade PFOS and PFOA [14,29]. Also, peroxidases degrade PFOA [13]. These enzymes are produced in plants, where they can be active. But they can also be released into the rhizosphere, where they can degrade and transform organics [30]. This means that PFAS may be degraded in the rhizosphere and/or in the plant tissue by these enzymes. In this study, it might be the reason in the tissue of the plants but not in the plant surroundings, since no such enzymes were detected in our study.

We conclude that plants are able to remove PFAS from the water and longer the duration of contact with the plant the more is the decrease in PFAS concentration in the water. Wetland plants seem to be best suited for this purpose.

\section{Acknowledgement}

The analysis in this work was financed by PhytoEnvitech $A B$ and Ramböll AB. We thank Emilie Jansson, Emre Boynukisa and Kimberly Arfwedson for help with two of the experiments.

\section{References}

1. Sohlenius AK, Andersson K, Bergstrand A, Spydevold O, De Pierre JW (1994) Effects of perfluorooctanoic acid, a potent peroxisome proliferator in rat, on Morris hepatoma $7800 \mathrm{C} 1$ cells, a rat cell line. Biochem Biophys 1213(1): 63-74.

2. Trudel D, Horowitz L, Wormuth M, Scheringer M, Cousins IT, Hungerbühler K (2008) Estimating consumer exposure to PFOS and PFOA. Risk Anal 28(2): 251-269. 
3. Hamid H, Li LY (2016) Role of wastewater treatment plant in environmental cycling of poly- and perfluoroalkyl substances. Ecocycles 2(2): 43-53

4. Domingo JL (2012) Health risks of dietary exposure to perfluorinated compounds. Environment International 40: 187-195.

5. Zhao H, Guan Y, Zhang G, Zhang Z, Tan F (2012) Uptake of perfluorooctane sulfonate (PFOS) by wheat (Triticum aestivum L.) plant. Chemosphere 91(2): 139-144.

6. Blaine AC, Rich CD, Sedlacko EM, Hyland KC, Stushnoff C, et al. (2014) Perfluoroalkyl acid uptake in lettuce (Lactuca sativa) and strawberry (Fragaria ananassa) irrigated with reclaimed water. Environmental Science \& Technology 48(24): 14361-14368.

7. Wen B, Li L, Zhang H, Ma Y, Shan XQ, et al. (2014) Field study on the uptake and translocation of perfluoroalkyl acids (PFAAs) by wheat (Triticum aestivum L.) grown in biosolids-amended soils. Environmental Pollution 184: 547-554.

8. Xiao Zhong Hu XZ, Hu DC (2009) Effects of perfluorooctanoate and perfluorooctane sulfonate exposure on hepatoma Hep G2 cells. Arch Toxicol 83(9): 851-861

9. Stahl T, Heyn J, Thiele H, Hünter J, Failing K, Georgii S, Brunn H (2009) Carryover of perfluorooctanoic acid (PFOA) and perfluorooctanesulfonate (PFOS) from soil to plants. Archives of Environmental Contamination and Toxicology 57(20): 289-298.

10. Felizeter S, McLachlan M, De Voogt P (2014) Root uptake and translocation of perfluorinatedalkyl acids by three hydroponically grown crops. Journal of Agricultural and Food Chemistry 62(15): 3334-3342.

11. Chen YC, Lo SL, Lee YC (2012) Distribution and fate of perfluorinated compounds (PFCs) in a pilot constructed wetland. Desalination and Water Treatment 37(1-3): 178-184.

12. Wang P, Zhang M, Lu Y, Meng J, Li Q et al. (2020) Removal of perfluoalkyl acids (PFAAs) throughfluorochemical industrialand domestic wastewater treatment plants and bioaccumulation in aquaticplants in river and artificial wetland. Environment International 129: 76-85.

13. Colosi LM, Pinto RA, Huang Q Weber WJ (2009) Peroxidase-mediated degradation of perfluorooctanoic acid. Environmental toxicology and chemistry 28(2): 264-271.

14. Luo Q, Lu J, Zhang H, Wang Z, Feng M, Chiang SYD, et al. (2015) Laccase-catalyzed degradation of perfluorooctanoic acid. Environ Sci Technol Lett 2: 198-203.

15. Tobimatsu Y, Schuetz M (2019) Lignin polymerization: how do plants manage the chemistry so well? Current Opinion in Biotechnology 56 75-81.

16. Bodini SF, Cicalini AR, Santori F (2011) Rhizosphere dynamics during phytoremediation of olive mill wastewater. Bioresource Technology
102(6): 4383-4389.

17. Landberg T, Greger M (2002) Differences in oxidative stress in heavy metal resistant and sensitive clones of Salix viminalis. J Plant Physiol 159(1): 69-75.

18. Javed MT, Stoltz E, Lindberg S, Greger M (2013) Changes in pH and organic acids in mucilage of Eriophorum angustifolium roots after exposure to elevated concentrations of toxic elements. Environ Sci Pollut Res 20(3): 1876-1880.

19. Schück M, Greger M (2020) Plants traits related to the heavy metal removal capacities of wetland plants. Int J Phytorem 22(4): 427-435.

20. Fritioff $\AA$, Greger M (2003) Aquatic and Terrestrial Plant Species with Potential to Remove Heavy Metals from Stormwater. International Journal of Phytoremediation 5(3): 211-224.

21. Bergqvist C, Greger M (2012) Arsenic accumulation and speciation in plants from different habitats. Applied Geochemistry 27(3): 615-622.

22. Greger M (2004) Metal availability, uptake, transport and accumulation in plants. In: MNV Prasad, J Hagemeyer (Eds.), Heavy Metal Stress in Plants - From Molecules to Ecosystems. (2 ${ }^{\text {nd }}$ edn), Springer Verlag, Heidelberg, Germany, pp. 1-27.

23. Felizeter S, McLachlan MS, de Voogt P (2012) Uptake of perfluorinated Alkyl acids byHydroponically grown lettuce (Lactuca sativa). Environ Sci Technol 46: 11735-11743.

24. Ghisi R, Vamerali T, Manzetti S (2019) Accumulation of perfluorinated alkyl substances (PFAS) in agricultural plants: A review. Environmental Research 169: 326-341.

25. Krippner J, Brunn H, Falk S, Georgii S, Schubert S, et al. (2014) Effects of chain length and $\mathrm{pH}$ on the uptake and distribution of perfluoroalkyl substances in maize (Zea mays). Chemosphere 94: 85-90.

26. Garcia Valcarcel AI, Molero E, Escorial MC, Chueca MC, Tadeo JL (2014) Uptake of perfluorinated compounds by plants grown in nutrient solution. Science of the Total Environment 472: 20-26.

27. Rodriguez CER, Galan MAG, Blanquez P, Cruz MSD, Barcelo D, et al. (2012) Continuous degradation of a mixture of sulfonamides by Trametes versicolor and identification of metabolites from sulfapyridine and sulfathiazole. J Hazard Mater 213-214: 347-354.

28. Greger M, Landberg T (1999) Use of willow in phytoextraction. Int J Phytoremed 1(2): 115-123.

29. Luo Q Yan X, Lu J, Huang Q (2018) Perfluorooctanesulfonate degrades in a laccase-mediator system. Environ Sci Technol 52(18): 1061710626.

30. Schnoor JL, Licht LA, McCutcheon SC, Wolfe NL, Carreira LH (1995) Phytoremediation of Organic and Nutrient Contaminants. Environmental Science \& Technology 29(7): 318A-323A. 